\title{
Mixotrophy, allelopathy and the population dynamics of phagotrophic algae (cryptophytes) in the Darss Zingst Bodden estuary, southern Baltic
}

\author{
A. C. Hammer ${ }^{1,2}$, J. W. Pitchford ${ }^{1, *}$ \\ ${ }^{1}$ Department of Biology / Area 12, University of York, York YO10 5YW, UK \\ ${ }^{2}$ Present address: Max-Planck-Institute for Demography, Konrad-Zuse-Str. 1, 18055 Rostock, Germany
}

\begin{abstract}
Seasonal plankton dynamics in the Darss Zingst Bodden Chain (DZBC), a southern Baltic estuary, are characterised by summer cyanophyte/chlorophyte dominance, but with winter blooms of mixotrophic cryptophytes, particularly associated with periods of ice cover. Analysis and simulation of a mixotrophic Lotka-Volterra competition model shows that coexistence of algae and cryptophytes is unlikely under static conditions, with seasonal or stochastic variation in parameters, as well as with time lags. However, incorporating production by cyanophytes/chlorophytes of nontoxic allelopathic substances allows stable coexistence of algae and mixotrophs. When parameterised using empirical DZBC data for light, temperature and ice cover, the model gives a good representation of cryptophyte dynamics and bloom formation. We conclude that both mixotrophy and allelopathy are necessary ingredients of community coexistence and dynamics in the DZBC.
\end{abstract}

KEY WORDS: Cryptophytes $\cdot$ Allelopathy $\cdot$ Mixotrophy $\cdot$ Plankton dynamics $\cdot$ Estuary $\cdot$ Cyanobacteria

\section{INTRODUCTION}

Coexistence of competing species poses a classic question in theoretical ecology. In most natural habitats, numerous competing species are able to coexist, seemingly limited by only a few resources. This contradicts a fundamental tenet in theoretical ecology, the 'competitive exclusion principle', predicting exclusion of all but the best adapted species for each limiting factor (e.g. Gause \& Witt 1935). This puzzle is most striking in phytoplankton communities, where a large number of species coexist in an unstructured environment, all competing for a small number of limiting resources. To solve this so-called 'paradox of plankton', Hutchinson (1961) proposed that natural phytoplankton communities are organised by processes beyond resource competition, including inter-species interactions, seasonal habitat variability and dispersal.

The competitive exclusion principle is supported by the Lotka-Volterra differential equation model for 2 competing species (review in Wangersky 1978); its failure, therefore, to model realistic competing plankton communities suggests such a model is an oversimplification. More complex models demonstrate that non-equilibrium resource supply (Tilman 1977), periodically fluctuating coefficients (e.g. Namba \& Takahashi 1993), or delays/time lags (e.g. Wangersky \& Cunningham 1957) can promote coexistence and enhance diversity, supporting Hutchinson's argument. Cloern \& Dufford (2005) summarise fundamental processes promoting phytoplankton coexistence: habitat heterogeneity at all scales; community shifts in response to global climate cycles; turbulent mixing as a physical process that selects species by size and morphology; species interactions across trophic levels, e.g. species-specific viruses; or mixotrophy that allows some algal species to tap organic nutrient pools and function at multiple trophic levels (the strategy of 'eating one's competitor', Thingstad et al. 1996).

Mixotrophic algae, including the ubiquitous and ecologically important cryptophytes, are key components of phytoplankton communities in several 
aquatic systems (e.g. Wiedner \& Nixdorf 1998, Roberts \& Laybourn-Parry 1999, Cloern \& Dufford 2005).

Simple coexistence of competing algal species is, however, an incomplete description; plankton populations are notoriously dynamic. Seasonal succession and bloom formation are fundamental to these dynamics (review in Roelke et al. 2004), and any coexistence argument which ignores these phenomena is therefore of limited value. The present study investigates the interplay between coexistence and dynamics, using detailed data from a Baltic Sea estuary, the Darss Zingst Bodden chain (DZBC). The semi-enclosed eutrophic, shallow, wind-mixed and tideless lagoon on the southern Baltic coast is of great ecological importance, serving as a filtering system, transformation zone and sink for land-borne nutrients and pollutants, as well as providing habitats for a large variety of animals and plants (Schernewski \& Schiewer 2002). It is characterised by such features as fluctuation of ecosystem parameters and intensive chemical, physical and biological processes. Phyto- and zooplankton form important components of the pelagic food webs that participate in producing and structuring the matter and energy in the ecosystem. The most prominent taxonomic groups in the DZBC (Chlorophyceae, Cyanophyceae), typically amount to $90 \%$ of the total phytoplankton biovolume. These algal groups dominate during most of the year, but in winter there is a substantial increase in the biomass of mixotrophic cryptophytes (Rhodomonas lacustris, R. baltica and $R$. salina) (up to 26-fold compared to the annual mean; Schumann et al. 2005) and in cold winters this group is dominant. Strikingly, cryptophytes can reach extremely high abundances (blooms) during periods of persistent ice cover (Wasmund 1994; see Fig. 5 present paper).

According to Wasmund (1994) and Schubert et al. (2001), temperature, light intensity and attenuation of light seem to be the decisive factor in the $\mathrm{DZBC}_{\text {; }}$ mixing of the water column and grazing are of minor importance for the seasonal periodicity of the phytoplankton. Experiments suggest that mixotrophy is important for the success of cryptophytes in winter (Roberts \& LaybournParry 1999, Hammer 2003), as they are unlikely to meet all of their carbon requirements from photosynthesis (Hammer et al. 2002). Mixotrophy allows survival in conditions of low radiation, temperature, salinity, $\mathrm{pH}$ and a stable water column.

Allelopathy, loosely defined as the release of extracellular compounds that inhibit the growth of other microorganisms, has attracted a growing interest in theoretical ecology (Maynard-Smith 1974, Durrett \& Levin 1997, Zhen \& Ma 2002, Mukhopadhyay et al. 2003, Hulot \& Huisman 2004, Sole et al. 2005). Field studies on the role of allelopathy in natural plankton communities are rare (Legrand et al. 2003, Suikkanen et al. 2005), but it is argued that allelopathic interactions are only significant where there are high biomass concentrations of phytoplankton (Schmidt \& Hansen 2001), which can be understood in terms of the diffusion of the allelochemicals (Siegel 1998).

Recent investigations conducted with algal species from the southern Baltic Sea show that cryptophytes are particularly susceptible to allelochemicals of frequently bloom-forming cyanobacteria Nodularia, Aphanizomenon and Anabaena (Suikkanen et al. 2004), possibly due to their higher membrane permeability. Nodularia spumigena produces hepatotoxin, and has been reported to have toxic effects on aquatic and terrestrial organisms (Rinehart et al. 1988), but the 2 strains of Aphanizomenon flos-aquae and Anabaena spp. are generally not toxic in the Baltic (Sivonen et al. 1989). This suggests that allelopathy of these cyanobacteria was due to non-toxic compounds; correlations between toxin (hepatotoxin) production and allelopathy were not found (Suikkanen et al. 2004). The field studies of Suikkanen et al. (2005) support these results and show that cryptophytes are the only group to be negatively affected by cyanobacteria filtrates; indeed cyanobacteria filtrates had stimulatory effects on other groups. A principal outcome of our modelling exercise is that allelopathy is important, together with mixotrophy, for the coexistence and seasonal dynamics of cyanobacteria and cryptophytes in the Baltic.

The present paper develops a mathematical model to represent the seasonal and transient dynamics in the DZBC. The model shows the dynamic behaviour that leads us to consider the succession of cryptophyte blooms and coexistence of species in phytoplankton communities as influenced by temporal changes in environmental conditions and life-history traits. The purpose is to thoroughly explore the plausibility of the mixotrophy hypothesis as an explanation of the winter bloom forming of cryptophytes in the DZBC. The objective is to put sensible constraints on the possible mechanisms governing phytoplankton coexistence and dynamics. We include data from detailed laboratory and field studies. Nevertheless, the model is kept as simple as possible to facilitate mathematical analysis and ecological interpretation.

\section{OBSERVATIONAL DATA AND MODEL ASSUMPTIONS}

Long-term observations across the habitat gradients of the DZBC and ecophysiological studies (Wasmund 1994, Hammer et al. 2002, Hammer 2003, Schumann et 
al. 2005, Suikkanen et al. 2004, 2005) provide an appropriate data set for understanding the fundamental principles shaping phytoplankton communities, as summarised below.

Environmental variables. Data on the major physical environmental variables affecting production rate of the DZBC phytoplankton, light and temperature were based on averages of observations made in Zingst (Fig. 1, Hammer 2003). Daily averages of underwater light in the DZBC were calculated from simulated surface light courses after correction for reflection according to Walsby (1997).

Nutrients. Schiewer et al. (1984) conclude that phytoplankton population growth follows its normal seasonal periodicity irrespective of growth limitations by nutrients. Despite possible slight spring and summer phosphate and nitrate limitations (Wasmund 1994), nutrient limitation is not included in the model.

Grazing. For the DZBC, the influence of grazing seems to be low, and cannot balance phytoplankton growth. Copepods, i.e. Eurytemora affinis, peak once in May and in some years again in autumn, but can never substantially decrease phytoplankton biomass (Wasmund \& Heerkloß 1993). No distinct relationship between phytoplankton and zooplankton biomass was found, but some selective grazing on chlorophytes, and avoidance of cyanophytes, could be observed (Wasmund \& Heerkloß 1993). Due to the high nutritional value and easy digestibility of cryptophytes (Klaveness 1989), a slight preference for them is included in the model during maximum copepod abundance in spring.

Phytoplankton groups. We form functional phytoplankton groups, as this will allow a general insight into phytoplankton dynamics. The dominant phytoplankton, cyanophytes and chlorophytes (Schumann et al. 2005), are represented in the model as a single group. The cryptophytes form the second group. Long-

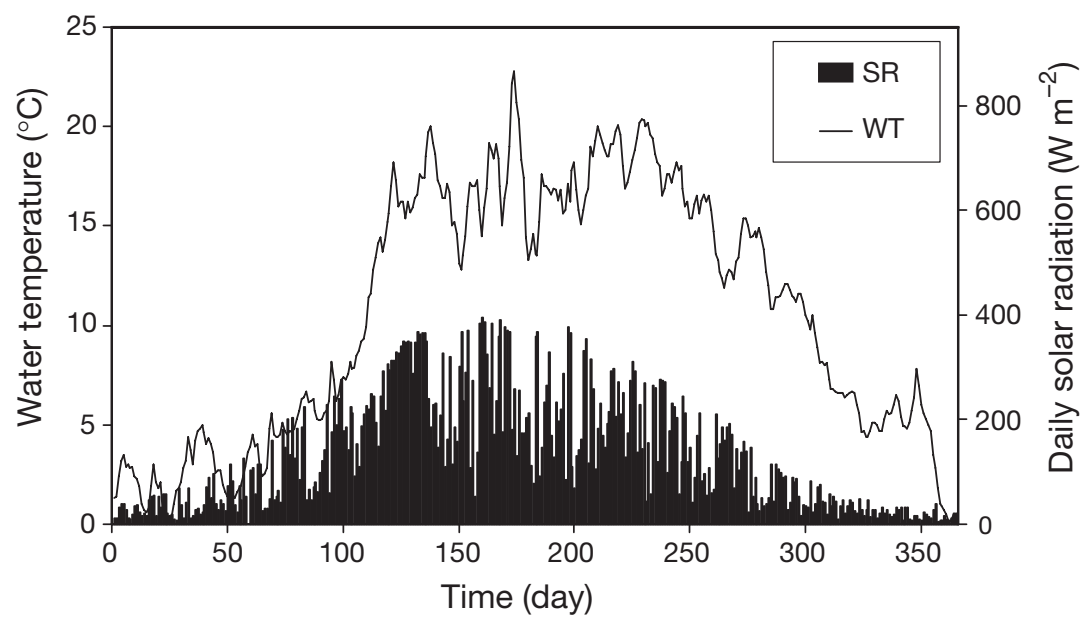

Fig. 1. Typical annual cycle of daily solar radiation (SR) and water temperature (WT) at one DZBC station (Zingst, 2004) (from Hammer 2003) term series are available on the annual cycle of abundance of phytoplankton in the DZBC (Wasmund 1994, Schumann et al. 2005).

\section{MODELS: MIXOTROPHIC AND MIXOTROPHIC-ALLELOPATHIC}

Consider a simplified ecosystem where 2 groups of 'phytoplankton' compete for survival: Phototrophic algae A (comprising the 2 dominant DZBC algal groups, cyanophytes and chlorophytes) with biomass $A$ and cryptophytes $C$ with biomass $C$. Assume that the growth rate of each group decreases due to competition for light and other limiting factors. Further, it is assumed that nutrient concentrations, grazing and vertical migration have negligible influence on phytoplankton dynamics (see section 'Observational data and model assumptions').

Suppose that one group, the cryptophytes $\mathrm{C}$, has the potential to be heterotrophic/phagotrophic. If the effects of seasonality (e.g. of growth rates) are ignored, the dynamics of the system may be described by the following differential equations (cf. Hammer \& Pitchford 2005):

$$
\begin{gathered}
\frac{\mathrm{d} A}{\mathrm{~d} t}=A r_{\mathrm{A}}\left(1-\frac{A+C}{K}\right)-\mu_{\mathrm{A}} A \\
\frac{\mathrm{d} C}{\mathrm{~d} t}=C p_{(T, L)} r_{\mathrm{C}}\left(1-\frac{A+C}{K}\right)+\left(1-p_{(T, L)}\right) \gamma m B C-\mu_{\mathrm{C}} C
\end{gathered}
$$

The parameter $p_{(T, L)}$ describes the preference of the cryptophytes for being phototrophic. The parameters $r_{\mathrm{A}}$ and $r_{\mathrm{C}}$ represent the algal and cryptophyte growth rate, respectively. The product $m B$ is the cryptophyte grazing rate on bacteria ( $m$ is an encounter rate, $B$ is bacterial concentration) and $\gamma$ represents the efficiency of converting bacterial biomass to $\mathrm{C}$ biomass $(C): \gamma<1$, so that $\gamma m B$ is the phagotrophic growth rate of the cryptophytes. The parameters $\mu_{\mathrm{A}}$ and $\mu_{\mathrm{C}}$ quantify the per capita rate of $\mathrm{A}$ and $\mathrm{C}$ external mortality. Finally, A and $\mathrm{C}$ share the same carrying capacity $K$. Because nutrient dynamics and, as a consequence, interspecific competition are not explicitly taken into account, in this sense interspecific and intraspecific competition are at the same intensity.

Data records for parameter values and optimisation of this model originate from published reports: for $r_{\mathrm{A}}$ (dominant DZBC algal species of chlorococcal chlorophytes and cyanobacteria), we used the literature reported in 'Obser- 
vational data and model assumptions'; for $m$, the encounter rate for cryptophytes on bacteria in coastal zones, the calculations from MacKenzie \& Kiørboe (1995), and for $B$ we took the average DZBC bacterial concentration (Schumann et al. 2003). The calculated grazing rate is in good agreement with experimental grazing rates or data from the Antarctic (Roberts \& Laybourn-Parry 1999). For $r_{\mathrm{C}}$ and $p_{(T, L)}$, experimental data exist (Hammer et al. 2002, Hammer 2003).

Table 1 provides definitions, brief descriptions and typical values for the parameters in Eqs. (1) \& (2).

Recent studies of cryptophyte growth in the southern Baltic Sea highlight the importance of another parameter affecting coexistence between algae - the negative effect of common Baltic cyanobacteria on cryptophytes, by releasing allelopathic but non-toxic chemicals that significantly inhibit the growth of sensitive cryptophytes (Suikkanen et al. 2004, 2005). Previously, interactions between cyanobacteria and the rest of the Baltic Sea phytoplankton community were largely unknown. Suikkanen et al. $(2004,2005)$ showed in laboratory and field experiments that all cyanobacteria inhibited the growth of the cryptophyte Rhodomonas sp. Protein phosphatase, involved in the synthesis of the phycobiliprotein light-harvesting complex in cryptophytes, allowing photosynthesis to function with high efficiency under limited irradi- ance, might be especially vulnerable to allelopathic chemicals (Eriksson et al. 1990). This interference between competitors is readily incorporated into our model, although its detailed formulation is necessarily speculative at this stage. The mixotrophic preference function now involves a preference for being phototrophic, which also depends on the abundance of algae. This can be achieved by multiplying the original $p_{(T, L)}$ by an allelopathic factor $p_{(\mathrm{A})}$. For simplicity we use:

$$
p_{(\mathrm{A})}=1-\frac{A}{K}
$$

This simple function assumes a linear decrease in the cryptophytes' autotrophic ability due to the allelopathic effect of algae. In this sense it is equivalent to the (ostensibly simpler) allelopathic interaction used by Mukhopadhyay et al. (2003) and Sole et al. (2005).

The mathematical model then becomes:

$$
\begin{gathered}
\frac{\mathrm{d} A}{\mathrm{~d} t}=A r_{\mathrm{A}}\left(1-\frac{A+C}{K}\right)-\mu_{\mathrm{A}} A \\
\frac{\mathrm{d} C}{\mathrm{~d} t}=C p_{(T, L)}\left(1-\frac{A}{K}\right) r_{\mathrm{C}}\left(1-\frac{A+C}{K}\right) \\
+\left[1-p_{(T, L)}\left(1-\frac{A}{K}\right)\right] \gamma m B C-\mu_{\mathrm{C}} C
\end{gathered}
$$

\begin{tabular}{|c|c|c|c|}
\hline Symbo & Description & ical value and/or units & Source \\
\hline$C$ & Cryptophyte biomass & $\mu g^{-1} \mathrm{~N}^{-1}$ & \\
\hline$A$ & $\begin{array}{l}\text { Biomass of dominant DZBC algal species } \\
\text { (chlorococcal chlorophytes and cyanobacteria) }\end{array}$ & $\mu g^{-1} \mathrm{~N} \mathrm{l}^{-1}$ & \\
\hline$T$ & Daily underwater temperature & ${ }^{\circ} \mathrm{C}$ & \\
\hline$L$ & Daily underwater light intensity & $\mathrm{mol} \mathrm{m}^{-2}$ & \\
\hline$p_{(T, L)}$ & $\begin{array}{l}\text { Preference of cryptophytes for being phototrophic } \\
\text { as a function of light }(L) \text { and temperature }(T)\end{array}$ & $0.07-0.97$ & Hammer (2003) \\
\hline$r_{\mathrm{C}}$ & Phototrophic growth rate of cryptophytes & $0-0.64 \mathrm{~d}^{-1}$ & $\begin{array}{l}\text { Ojala (1993), Gervais (1997), } \\
\text { Hammer et al. (2002), Hammer (2003) }\end{array}$ \\
\hline$r_{\mathrm{A}}$ & $\begin{array}{l}\text { Average growth rate of dominant DZBC algal } \\
\text { species (chlorococcal chlorophytes and cyanobacteria) }\end{array}$ & $0-0.78 \mathrm{~d}^{-1}$ & Ojala (1993), Henley \& Yin (1998) \\
\hline$m$ & $\begin{array}{l}\text { Encounter rate of cryptophytes and bacteria } \\
\text { in coastal zone }\end{array}$ & $1 \times 10^{-7} \mathrm{lpg}^{-1} \mathrm{~N} \mathrm{~d}^{-1}$ & MacKenzie \& Kiørboe (1995) \\
\hline$B$ & Average DZBC bacterial concentration & $4 \times 10^{-7} \mathrm{pg}^{-1} \mathrm{~N} \mathrm{l}^{-1}$ & Schumann et al. (2003) \\
\hline$m B$ & Cryptophyte grazing rate on DZBC bacteria & $0.5-4 \mathrm{~d}^{-1}$ & $\begin{array}{l}\text { Product of } m \text { and } B ; \text { Roberts \& } \\
\text { Laybourn-Parry (1999), Hammer (2003) }\end{array}$ \\
\hline$\gamma$ & Efficiency of converting bacterial biomass to $\mathrm{C}$ biomass & $0.1-0.2$ & Review in Straile (1997) \\
\hline$\gamma m B$ & Phagotrophic growth rate of cryptophytes & $0.05-0.4 \mathrm{~d}^{-1}$ & Product of $m B$ and $\gamma_{i}$ Hammer (2003) \\
\hline$\mu_{\mathrm{C}}$ & Per capita rate of $\mathrm{C}$ external mortality & $0.1-0.15 \mathrm{~d}^{-1}$ & $\begin{array}{l}\text { Kumar et al. (1991), Oguz et al. (1999), } \\
\text { Hammer \& Pitchford (2005), } \\
\text { Kimmerer et al. (2005) (Estuary) }\end{array}$ \\
\hline$\mu_{\mathrm{A}}$ & Per capita rate of A external mortality & $0.1 \mathrm{~d}^{-1}$ & $\begin{array}{l}\text { Kumar et al. (1991), } \\
\text { Hammer \& Pitchford (2005), } \\
\text { Kimmerer et al. (2005) (Estuary) }\end{array}$ \\
\hline$K$ & Environmental carrying capacity $K$ & $108 \mu g^{-1} \mathrm{~N} \mathrm{l}^{-1}$ & $\begin{array}{l}\text { Kumar et al. (1991), } \\
\text { Hammer \& Pitchford (2005) }\end{array}$ \\
\hline$p_{(\mathrm{A})}$ & Allelopathic factor & $0.45-1$ & Present study \\
\hline
\end{tabular}

Table 1. Biological variables and parameters used in numerical simulation (DZBC: Darss Zingst Bodden Chain) 
i.e. the preference for being phototrophic not only depends on environmental conditions, light intensity and temperature, but also on the abundance of algae. Note that, in the absence of algae, the $\mathrm{C}$ dynamics at low density are identical to those in Eq. (2), with an exponential growth phase controlled by both photosynthesis and predation on bacteria. Growth rates $r_{\mathrm{A}}$ and $r_{\mathrm{C}}$ are held constant for the purposes of analysis (Expt 4), but are more properly regarded as functions of time in data-driven simulations (see 'Discussion').

\section{EXPERIMENTS}

The investigation is described as a series of theoretical 'experiments', each of which asks whether a particular phenomenon can explain the observed coexistence and dynamics of cryptophytes and autotrophs.

\section{Expt 1-Can mixotrophy explain coexistence?}

Appendix 1 shows that model $(1,2)$, in the absence of external disturbance, exhibits competitive exclusion. Depending on $p_{(T, L)}$, the preference of the cryptophytes for being phototrophic, either cryptophytes or algae are excluded. A low preference $\left(p_{(T, L)}<0.5\right)$ leads to exclusion of algae (Fig. 2, equilibrium $C$ ), whereas $p_{(T, L)}>0.5$ causes exclusion of cryptophytes (not shown). Under constant conditions the mixotrophic ability of

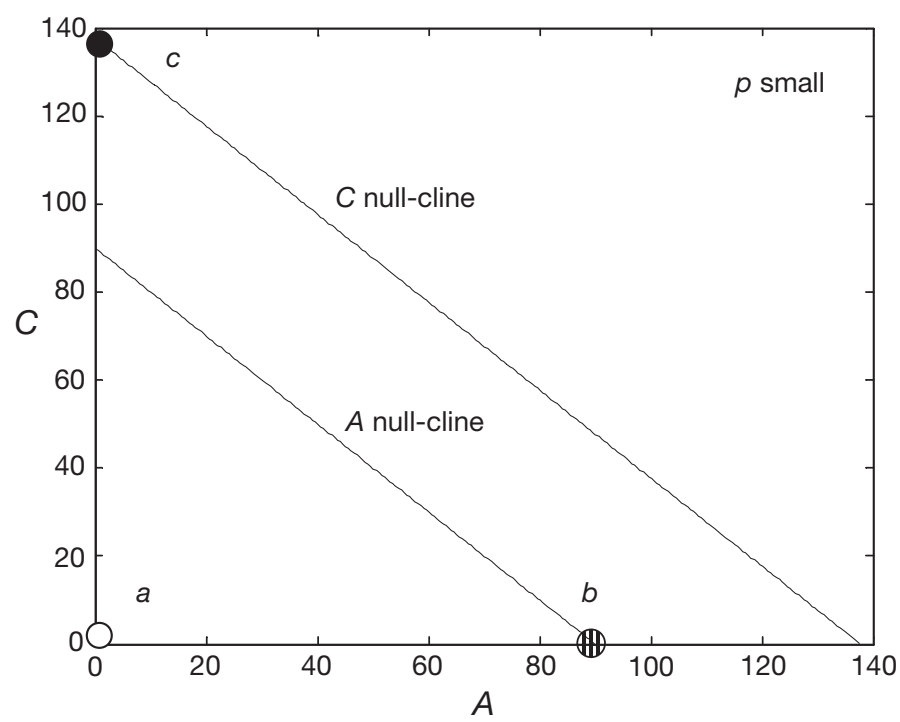

Fig. 2. Null-cline structure, i.e. the lines (curves, more generally) on which $\mathrm{d} A / \mathrm{d} t=0$ or $\mathrm{d} C / \mathrm{d} t=0$, for $A / C$ system without allelopathy (Expt 1, Eqs. 1 \& 2) (O: unstable equilibrium; (ID: saddle point; $\mathbf{0}$ : stable equilibrium). Units for $A$ and $C: \mu^{-1} \mathrm{~N}^{-1}$ the cryptophytes does not make them sufficiently different (i.e. sufficiently different preferences in resource usage) to avoid extinction.

\section{Expt 2-The role of environmental seasonality and stochastic fluctuations in coexistence and competition}

Expt 1 shows that simple steady-state arguments for coexistence are insufficient. However, this may be an overly restrictive requirement in a seasonally and stochastically variable environment. It may be that temporal changes in parameters move the system between regimes dominated by algae and cryptophytes, but that the overall effect is one of coexistence. Alternatively, it may be that the rate at which an inferior competitor is driven to extinction is so slow that, although the model predicts ultimate competitive exclusion, in practice long-term coexistence would be observed. Therefore model $(1,2)$ must be tested against known and quantified environmental changes.

\section{Expt 2a. Seasonality in growth rates}

Phototrophic growth rates of both competitors are allowed to seasonally oscillate at small amplitudes so that $r_{\mathrm{A}}$ and $r_{\mathrm{C}}$ become functions of time, $r_{\mathrm{A}}=r_{\mathrm{A}}(t), r_{\mathrm{C}}=$ $r_{\mathrm{C}}(t)$. Here, we use literature results for growth rates of cryptophytes (Ojala 1993, Gervais 1997) and Baltic estuarine cyanophyte and chlorophyte species (Ojala 1993, Henley \& Yin 1998) and our own experimental data from growth experiments with cryptophytes (Hammer et al. 2002, Hammer 2003) at varying light intensity and temperature:

$$
\begin{aligned}
& r_{\mathrm{A}}(t)=\frac{1}{2}\left[\sin \left(\frac{2 \pi t}{365}\right)+1\right]\left(r_{\mathrm{A} \max .}-r_{\mathrm{A} \min .}\right)+r_{\mathrm{A} \min .} . \\
& r_{\mathrm{C}}(t)=\frac{1}{2}\left[\sin \left(\frac{2 \pi t}{365}\right)+1\right]+\left(r_{\mathrm{C} \max .}-r_{\mathrm{C} \min .}\right)+r_{\mathrm{C} \min .}
\end{aligned}
$$

Numerical integration of model $(1,2)$ under the above modification does not promote coexistence; again the model shows competitive exclusion after a small number of annual cycles, with the dominant species being determined as in Expt 1 after growth parameters are temporally averaged. When the above-mentioned experimental data sets are more realistically applied using daily light and temperature combinations from the DZBC (years 1993 to 1998; Schumann et al. 2005) to drive $r_{\mathrm{A}}$ and $r_{\mathrm{C}}$, one again observes rapid competitive exclusion, with either cryptophytes or algae being dominant, de- 
pending on $p_{(T, L)}$. As in Expt $1, p_{(T, L)}<0.5$ leads to cryptophyte dominance, and $p_{(T, L)}>0.5$ to algal dominance.

In other words, seasonally oscillating phototrophic growth rates cannot be solely responsible for the coexistence and dynamics of $A$ and $C$.

Expt 2b. Seasonality in mixotrophy, $p_{(T, L)}$

Recent experimental data, taken from mixotrophic growth experiments at varying light intensities and temperatures (Hammer et al. 2002, Hammer 2003), show that the cryptophytes' preference for autotrophy, $p_{(T, L)}$, also changes. With decreasing temperature/light intensity the bloom-forming DZBC cryptophyte Rhodomonas salina is less capable of photoacclimation, i.e. light-harvesting protein synthesis is reduced. At the same time, organic carbon uptake increases, and, under winter conditions $\left(<30 \mu \mathrm{mol}\right.$ photons $\mathrm{m}^{-2} \mathrm{~s}^{-1}$, $<10^{\circ} \mathrm{C}$ ), this alga depends more strongly on organic carbon for nutrition than on photosynthesis. Incorporating these changes as in Expt 2a, both with and without additional forcing in growth rates, is still insufficient to explain coexistence. Using DZBC light and temperature data, the model exhibits rapid cryptophyte extinction in $<2 \mathrm{yr}$.

Expt 2c. Including periods of ice cover, i.e. zero phototrophic growth for $\sim 3$ mo

The intermittent occurrence of periods of ice cover ('ice winters') of around 3 mo is simulated by temporarily setting $r_{\mathrm{A}}$ and $r_{\mathrm{C}}$ to zero, leading temporarily to exponential heterotrophic growth of cryptophytes and exponential decrease of algae. Again, ecologically meaningful coexistence does not occur. More realistic simulation of the ice phenomenon, e.g. annual ice winters of $90 \mathrm{~d}, 90 \mathrm{~d}$ of ice cover every third year, random durations of ice cover between 0 and $90 \mathrm{~d}$ chosen independently each year, and applying DZBC ice data from 1993 to 1998, do not alter the conclusion; intermittent ice cover is not sufficient to explain the observed coexistence and dynamics.

\section{Expt 3 - The effect of time delays}

The model $(1,2)$ can be modified by considering the fact that cryptophytes have a highly efficient lightharvesting complex, which already allows early phototrophic growth under late winter/early spring conditions (e.g. Arrigo et al. 1993). This may be thought of as inducing an asynchrony in the competitors' response to their seasonally changing environment. Numerically this is implemented similarly to calculations in Expt 2a (above), but with the cryptophytes' response shifted forward in time by $s$.

$$
\begin{gathered}
r_{\mathrm{A}}(t)=\frac{1}{2}\left[\sin \left(\frac{2 \pi t}{365}\right)+1\right]\left(r_{\mathrm{A} \max .}-r_{\mathrm{A} \min .}\right)+r_{\mathrm{A} \min .} \\
r_{\mathrm{C}}(t)=\frac{1}{2}\left[\sin \left(\frac{2 \pi t}{365}+s\right)+1\right]\left(r_{\mathrm{C} \max .}-r_{\mathrm{C} \min .}\right)+r_{\mathrm{C} \min .}
\end{gathered}
$$

Similar equations have been studied by Wangersky \& Cunningham (1957) as variations on the standard Lotka-Volterra equations. If the 2 species are in complete synchrony, the ultimate result is elimination of one of the populations, but incorporating lags allows the populations to fluctuate and also allows reversals of the apparent direction of competition; such reversals cannot occur with the non-lag formulations.

However, when such lags are introduced to Eqs. (1) \& (2), parameterised appropriately for cryptophyte and algal competition in the Baltic estuary, there is again no practical scope for coexistence.

The results of Expts 1 to 3 suggest that seasonally or stochastically changing phototrophic growth rates, changes in the cryptophyte's mixotrophic ability and asynchrony in response to environmental change are insufficient to explain cryptophyte coexistence with purely phototrophic algae.

\section{Expt 4 - The role of allelopathy}

Appendix 2 shows that by including allelopathic effects the trivial steady state of Eqs. (1) \& (2), corresponding to competitive exclusion, may lose its stability; a stable non-trivial steady state is created. We argue that this is a plausible mechanism leading to coexistence between cryptophytes and algae (Fig. 3A, equilibrium $a$, approximately $p_{(T, L)}>0.3$, using parameters in Table 1).

If the preference for being phototrophic is very low (approximately $\left.p_{(T, L)}<0.3\right)$, so that the cryptophytes are almost entirely heterotrophic, as in winter; Fig. 3B), the $C$ null-cline moves upwards so that the 2 null-clines intersect in the region $A<0$, i.e. equilibrium a has negative $A$ and positive $C$ values and becomes a saddle and equilibrium $d$ becomes stable, resulting in a system dominated by cryptophytes to the exclusion of algae.

The alternative non-coexistent steady state, where the null-clines intersect for $A>0$ and $C<0$, and where consequently cryptophyte exclusion with $A=K$ becomes the stable equilibrium, is mathematically possible, but does not occur for any realistic combination of parameter values of our system. 

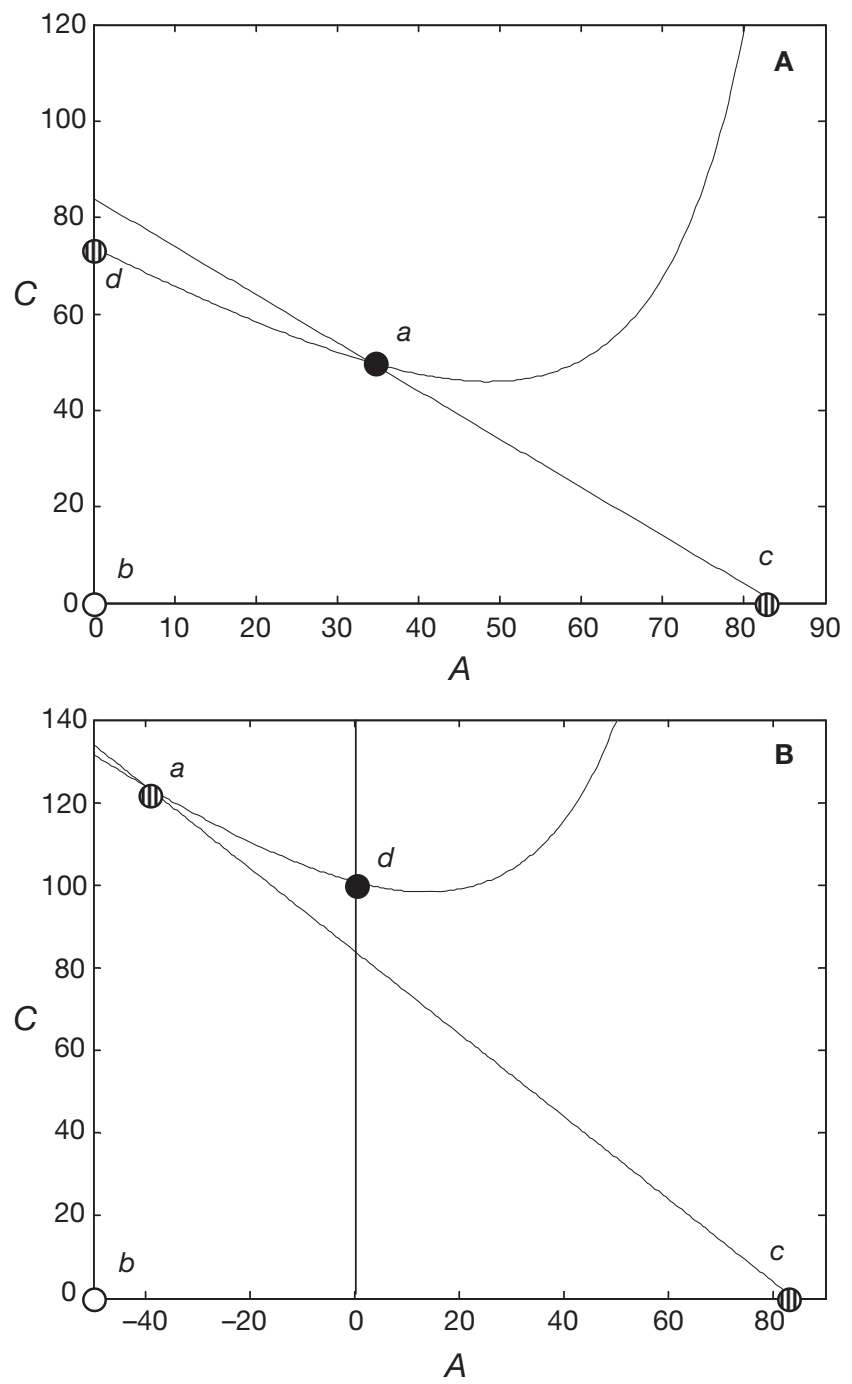

Fig. 3. Null-cline structure for $A / C$ system with allelopathy (Expt 4, Eqs. 3 \& 4), equilibria as defined in Appendix 2, stability of equilibria labelled as in Fig. 2: (A) high $p_{(T, L)}$ (summer conditions) and (B) low $p_{(T, L)}$ (winter conditions). Units for $A$ and $C: \mu^{-1} \mathrm{~N} \mathrm{l}^{-1}$; symbols as in Fig. 2

It is argued below that our system goes through the above-described scenarios (Fig. 3) in the course of the year (Fig. 4), with cryptophytes changing their mixotrophic ability under the combined influence of environmental and allelopathic factors and that these mechanisms provide a compelling description of coexistence, seasonal succession and cryptophyte bloom formation in the DZBC.

\section{DISCUSSION}

The above results suggest that allelopathy and mixotrophy are crucial to the outcome of competition between phytoplankton groups and, thereby, to com-

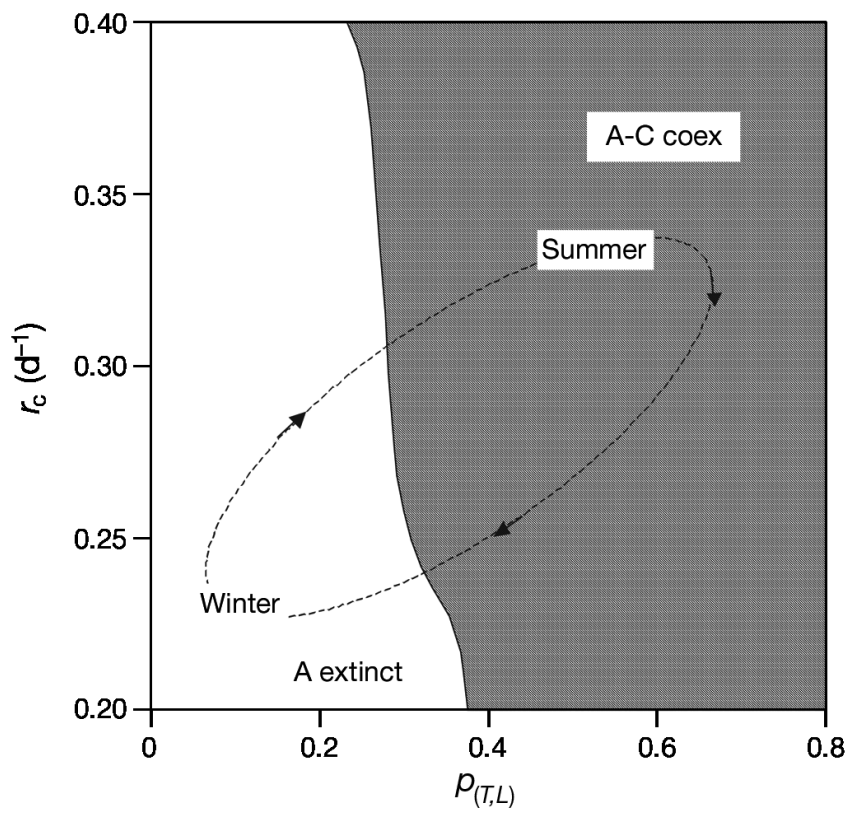

Fig. 4. Regions of coexistence in terms of $r_{\mathrm{C}}$ and $p_{(T, L)}$ for the model $(3,4)$ with allelopathy, showing a schematic annual trajectory through parameter space, calculated using the physiological constants of Table 1 and varying values of $r_{\mathrm{A}}$ (Schumann et al. 2005) and $r_{\mathrm{C}}$ (Hammer 2003)

munity structure and dynamics in the DZBC. The seasonal change in the cryptophyte's mixotrophic performance can be an important mechanism, driving the seasonal succession of the cryptophytes and promoting winter bloom formation.

Fig. 5 depicts the results of applying long-term environmental data from the DZBC to our model $(3,4)$, and clearly shows that the 2 groups can coexist indefinitely. The successional sequence in our model, summarised in Fig. 4, agrees well with investigations of phytoplankton seasonality in the Baltic Sea estuary between 1993 and 1998 (Fig. 5). Cryptophyte occurrence during winter is attributable to their tolerance of low temperatures and their ability to grow under low light conditions; in some winters they are the dominant group, but the non-mixotrophic algae are not driven to extinction. The overall picture of high chlorophyte/cyanophyte biomasses from spring until autumn is a robust feature. In mild winters the Chlorophyceae retain high biomasses, with few Cryptophyceae. In cold winters cryptophytes dominate the phytoplankton community. Light and temperature are the factors that trigger the switch in dominance to flagellates (Wasmund 1994, Wiedner \& Nixdorf 1998; shallow eutrophic lakes in Brandenburg, cyanophyte-dominated from early spring to late autumn, comparable to DZBC).

Fig. 4 shows the region of coexistence of $A$ and $C$ as a function of $p_{(T, L)}$ and $r_{\mathrm{C}}$, using model parameters given in Table 1 and the experimentally derived values 

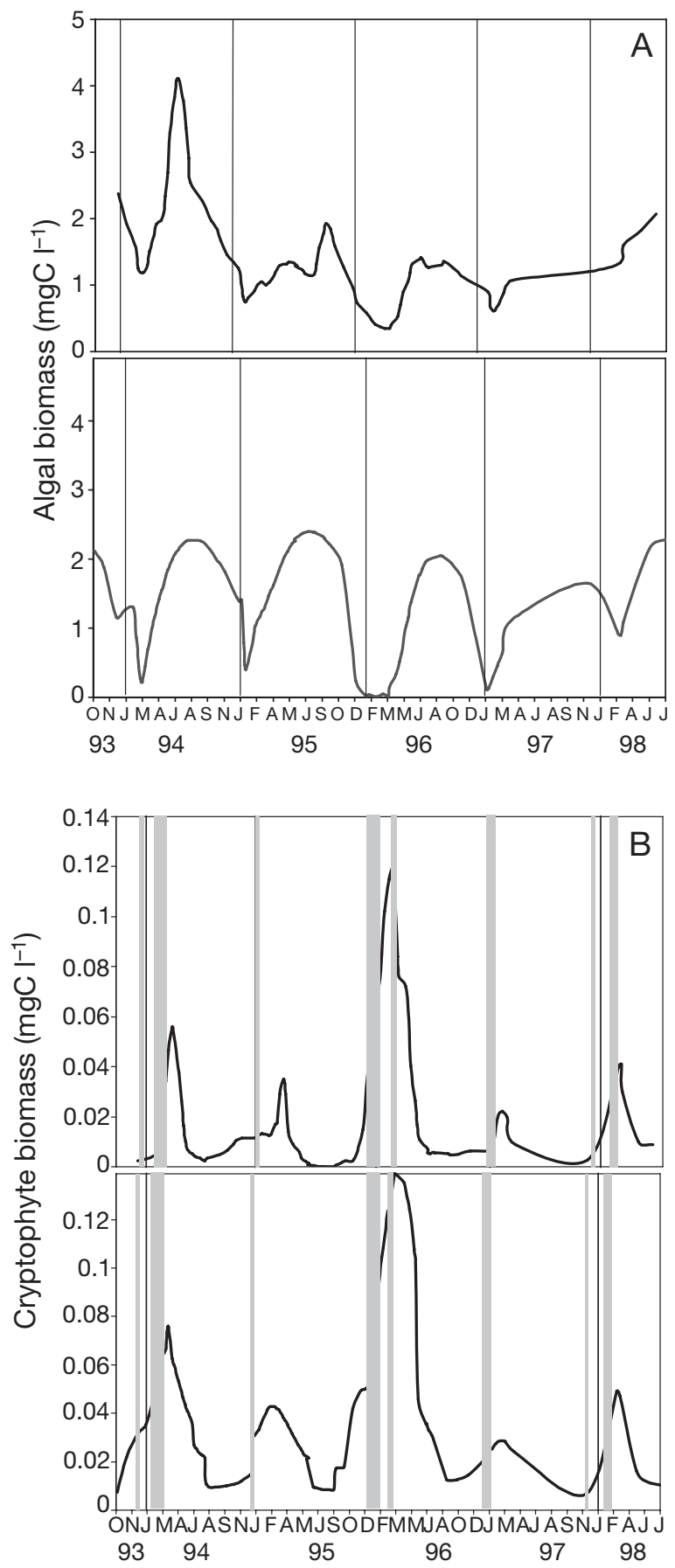

Fig. 5. Smoothed empirical data [upper panels-single exponential smoothing: $E_{t}=W \times Y_{t}+(1-W) \times E_{t-1}$, where weight $(W)=0.5, E_{t}$ is the smoothed observation for time period $t, Y_{t}$ is the actual observation for time period $t$ ] and modelling approach (lower panels) for: (A) algal biomass (sum of cyanophyte and chlorophyte biomass) and (B) cryptophyte biomass. Vertical grey bars correspond to periods of ice cover. Simulations based on temperature and light data for one DZBC station (Zingst) from 1993 to 1998. Model data were converted from $\mathrm{N}$ units into $\mathrm{C}$ units by using a molar $\mathrm{C}: \mathrm{N}$ ratio of 4.1 for cryptophytes (Hammer et al. 2003) and an average molar C:N ratio of 9.8 for dominant DZBC blue-green algae (Schumann et al. 2003) of $r_{\mathrm{A}}$ (Schumann et al. 2005) and $r_{\mathrm{C}}$ (Hammer 2003). For these parameters stable coexistence is guaranteed when $p_{(T, L)}>0.37$, but there is the possibility of dominance of $C$ for $p_{(T, L)}<0.37$. For selected values of $r_{\mathrm{A}}$ and $r_{\mathrm{C}}$ it was verified numerically that the saddle node bifurcation predicted in Appendix 2 was in agreement with the transition between coexistence and $\mathrm{C}$ dominance shown in Fig. 4. Note that, as illustrated by Fig. 4, the seasonal change of parameters is such that each of these scenarios (coexistence; C dominance) is likely to occur during an annual cycle.

Schiewer et al. (1988) concluded that the development of DZBC phytoplankton follows its normal seasonal periodicity irrespective of growth limitations by nutrients, and nutrient limitation is therefore ignored for now, but may be included in future research. According to Schiewer et al. (1988), temperature is the decisive factor for the seasonal periodicity at this location. Similarly, mixing of the water column and grazing are argued to be of minor importance (Wasmund 1994). A low impact of zooplankton grazing on the fluctuations (in phytoplankton numbers) was also reported from many other estuaries (review in Calbet 2001). Vertical structure is also ignored; although stratification may create opportunities for coexistence (Huisman et al. 1999), frequent wind-driven mixing of the shallow brackish waters of the DZBC make this mechanism of coexistence unlikely here. Regardless of the good qualitative agreement between the model results and observations, there are deviations. The daily population observations in Fig. 5 are exponentially smoothed (see Fig. 5 legend) to compensate for short-time-scale fluctuations, presumably caused by sudden local changes in light, temperature, or water conditions beyond the scope of our spatially homogeneous model. The failure to capture the abnormally large algal peak in 1994 can be explained by a temporary change in environmental carrying capacity, whilst similar tuning of (for example) the proposed allelopathy function could reduce the severity of the modelled winter algal decrease. The principal message, that the combination of mixotrophy and allelopathy can explain coexistence and annual cycles, remains robust.

By including new knowledge about allelopathy affecting Baltic Sea cryptophytes in our model, it is possible to demonstrate its importance in competitive coexistence and seasonal dynamics. Recent southern Baltic Sea experiments by Suikkanen et al. (2004, 2005) reveal that the cryptophyte Rhodomonas sp. (winter bloom forming in the DZBC) is negatively affected by all Baltic cyanobacteria, probably due to high membrane permeability (e.g. Rengefors \& Legrand 2001). The authors worked with a 1:1 relationship of cyanobacteria and cryptophytes, so any observed effects are likely to be underestimates of the 
natural situation, especially in the Baltic Sea estuary we observed, which was dominated by up to $92 \%$ cyanobacteria/chlorophytes. A model by Dubey \& Hussain (2000) found that the production by one species of an allelopathic chemical can cause extinction in a non-mixotrophic competitor species. Our model indicates that mixotrophy may alter this conclusion; allelopathy has a stabilising affect on the system where the affected species is mixotrophic, i.e. the interplay of allelopathy in cyanophytes and mixotrophy in cryptophytes leads to coexistence (Fig. 3), but allelopathy alone does not lead to coexistence. In this respect, mixotrophy is an important strategy affecting the dynamics of cryptophytes, i.e. allowing their winter bloom formation (Hammer 2003). In turbid estuaries, where photosynthesis is predominantly and strongly light limited, the capacity to acquire energy heterotrophically could provide a mechanism to survive and even promote phytoplankton coexistence and shape dynamics (Cloern \& Dufford 2005).

\section{CONCLUSIONS}

One of the most interesting phenomena associated with phytoplankton communities is the scope for coexistence on the part of many species within the same apparently homogeneous environment.

This study combines recent empirical results with simple models, focussing on competing phytoplankton groups in a Baltic Sea estuary. The mixotrophic ability of one of the groups (cryptophytes) depends on temperature and light conditions; the other group (cyanophytes) produces an allelochemical, which is deleterious to the mixotrophs. It is shown that, when combined, these 2 physiological properties lead to robust coexistence and realistic seasonal cycles. The mixotrophic cryptophyte population surges during (ice) winters, associated with a decline in the dominant algae, and the observed cryptophyte summer decline is associated with an increased allelopathic cyanophyte population.

It is well recognised that a resolution of the speciesassembly puzzle demands investigations grounded in autecology, organism interactions and life history (Cloern \& Dufford 2005). By including new experimental knowledge on the life cycle, behaviour and growth rates of the ubiquitous and ecologically important cryptophytes we move a step closer to constructing reliable numerical models of phytoplankton population dynamics at the species level. In turn, the mathematical framework we have developed could stimulate further field studies and experimental work on competition between phytoplankton species with different life-history traits.
Acknowledgements. This work was supported by a grant from the German Academy of Natural Scientists Leopoldina, BMBF-LPD 9901/8-100 to A.C.H. We are very grateful to 2 anonymous referees for their careful reviews and constructive comments.

\section{LITERATURE CITED}

Arrigo KR, Robinson DH, Sullivan CW (1993) Vertical profiles of the bio-optical and photophysiological properties of sea ice microalgae within the platelet layer of McMurdo Sound, Antarctica. J Phycol 98:173-185

Calbet A (2001) Mesozooplankton grazing effect on primary production: a global comparative analysis in marine ecosystems. Limnol Oceanogr 46:1824-1830

Cloern JE, Dufford R (2005) Phytoplankton community ecology: principles applied in San Francisco Bay. Mar Ecol Prog Ser 285:11-28

Dubey B, Hussain J (2000) A model for the allelopathic effect on two competing species. Ecol Model 129:195-207

Durrett R, Levin S (1997) Allelopathy in spatially distributed populations. J Theor Biol 185:165-171

Eriksson JE, Toivola D, Meriluoto JAO, Karaki H, Han YG, Hartshorne D (1990) Hepatocyte deformation induced by cyanobacterial toxins reflects inhibition of protein phosphatases. Biochem Biophys Res Commun 173:1347-1353

Gause GF, Witt AA (1935) Behavior of mixed populations and the problem of natural selection. Am Nat 69:596-609

Gervais F (1997) Light-dependent growth, dark survival, and glucose uptake by cryptophytes isolated from a freshwater chemocline. J Phycol 33:18-25

Hammer A (2003) Ökophysiologie mixotropher Cryptophyceen. PhD thesis, University of Rostock

Hammer AC, Pitchford JW (2005) The role of mixotrophy in plankton bloom dynamics, and the consequences for productivity. ICES J Mar Sci 62:833-840

Hammer A, Schumann R, Schubert H (2002) Light and temperature acclimation of Rhodomonas salina (Cryptophyceae): photosynthetic performance. Aquat Microb Ecol 29: $287-296$

Henley WJ, Yin Y (1998) Growth and photosynthesis of marine Synechococcus (Cyanophyceae) under iron stress. J Phycol 34:94-103

Huisman J, van Oostveen P, Weissing FJ (1999) Species dynamics in phytoplankton blooms: incomplete mixing and competition for light. Am Nat 154:46-68

Hulot FD, Huisman J (2004) Allelopathic interactions between phytoplankton: the roles of heterotrophic bacteria and mixing intensity. Limnol Oceanogr 49:1424-1434

Hutchinson G (1961) Paradox of plankton. Am Nat 95:137-145

Kimmerer W, Avent SR, Bollens SM, Feyrer F, Grimaldo LE, Moyle PB, Nobriga M, Visintainer T (2005) Variability in length-weight relationships used to estimate biomass of estuarine fish from survey data. Trans Am Fish Soc 134: 481-495

Klaveness D (1989) Biology and ecology of the Cryptophyceae: status and challenges. Biol Oceanogr 6:257-270

Kot M (2001) Elements of mathematical ecology. Cambridge University Press

Kumar SK, Vincent WF, Austin PC, Wake GC (1991) Picoplankton and marine food-chain dynamics in a variable mixed-layer - a reaction-diffusion model. Ecol Model 57: $193-219$

Legrand C, Rengefors K, Fistarol GO, Graneli E (2003) Allelopathy in phytoplankton-biochemical, ecological and evolutionary aspects. Phycologia 42:406-419 
MacKenzie BR, Kiørboe T (1995) Encounter rates and swimming behavior of pause-travel and cruise larval fish predators in calm and turbulent laboratory environments. Limnol Oceanogr 40:1278-1289

Maynard-Smith J (1974) Models in ecology. Cambridge University Press

Mukhopadhyay A, Tapaswi PK, Chattopadhyay J (2003) A space-time state-space model of phytoplankton allelopathy. Nonlinear Anal Real World Appl 4:437-456

Namba T, Takahashi S (1993) Competitive coexistence in a seasonally fluctuating environment. 2. Multiple stable states and invasion success. Theor Popul Biol 44:374-402

Oguz T, Ducklow HW, Malanotte-Rizzoli P, Murray JW, Shushkina EA, Vedernikov VI, Unluata U (1999) A physical-biochemical model of plankton productivity and nitrogen cycling in the Black Sea. Deep-Sea Res Part A 46: 597-636

Ojala A (1993) Effects of temperature and irradiance on the growth of 2 freshwater photosynthetic cryptophytes. J Phycol 29:278-284

Rengefors K, Legrand C (2001) Toxicity in Peridinium aciculiferum-An adaptive strategy to outcompete other winter phytoplankton? Limnol Oceanogr 46:1990-1997

Rinehart KL, Harada K, Namikoshi M, Chen C and 7 others (1988) Nodularin, microcystin, and the configuration of adda. J Am Chem Soc 110:8557-8558

Roberts EC, Laybourn-Parry J (1999) Mixotrophic cryptophytes and their predators in the Dry Valley lakes of Antarctica. Freshw Biol 41:737-746

Roelke D, Buyukates Y, Williams M, Jean J (2004) Interannual variability in the seasonal plankton succession of a shallow, warm-water lake. Hydrobiologia 513:205-218

Schernewski G, Schiewer U (2002) Status, problems and integrated management of Baltic coastal ecosystems. In: Schernewski G, Schiewer U (eds) Baltic coastal ecosystems: structure, function and coastal zone management. CEEDES-Series, Springer-Verlag, Berlin, p 1-16

Schiewer U, Börner R, Wasmund N (1988) Deterministic and stochastic influence of nutrients on phytoplankton function and structure in coastal waters. Kiel Meeresforsch Sonderh 6:173-183

Schiewer U, Börner R, Krüger B, Evert FK (1984) Estuarine phytoplankton response to nutrient changes in controlled ecosystem enclosures. Ophelia 201-212

Schmidt LE, Hansen PJ (2001) Allelopathy in the prymnesiophyte Chrysochromulina polylepis: effect of cell concentration, growth phase and pH. Mar Ecol Prog Ser 216:67-81

Schubert H, Sagert S, Forster RM (2001) Evaluation of the different levels of variability in the underwater light field of a shallow estuary. Helgol Mar Res 55:12-22

Schumann R, Rieling T, Görs S, Hammer A, Selig U, Schiewer U (2003) Viability of bacteria from different aquatic habitats. I. Environmental conditions and productivity. Aquat Microb Ecol 32:121-135
Schumann R, Hammer A, Görs S, Schubert H (2005) Winter and spring phytoplankton composition and production in a shallow eutrophic Baltic lagoon. Estuar Coast Shelf Sci 62:169-181

Siegel DA (1998) Resource competition in a discrete environment: Why are plankton distributions paradoxical? Limnol Oceanogr 43:1133-1146

Sivonen K, Kononen K, Carmichael WW, Dahlem AM, Rinehart KL, Kiviranta J, Niemela SI (1989) Occurrence of the hepatotoxic cyanobacterium Nodularia spumigena in the Baltic Sea and structure of the toxin. Appl Environ Microbiol 55:1990-1995

Sole J, García-Ladona E, Ruardij P, Estrada M (2005) Modelling allelopathy among marine algae. Ecol Model 183: 373-384

Straile D (1997) Gross growth efficiencies of protozoan and metazoan zooplankton and their dependence on food concentration, predator-prey weight ratio, and taxonomic group. Limnol Oceanogr 42:1375-1385

Suikkanen S, Fistarol GO, Graneli E (2004) Allelopathic effects of the Baltic cyanobacteria Nodularia spumigena, Aphanizomenon flos-aquae and Anabaena lemmermannii on algal monocultures. J Exp Mar Biol Ecol 308: 85-101

Suikkanen S, Fistarol GO, Graneli E (2005) Effects of cyanobacterial allelochemicals on a natural plankton community. Mar Ecol Prog Ser 287:1-9

Thingstad TF, Havskum H, Garde K, Riemann B (1996) On the strategy of 'eating your competitor': a mathematical analysis of algal mixotrophy. Ecology 77:2108-2118

Tilman D (1977) Resource competition between planktonic algae-experimental and theoretical approach. Ecology 58:338-348

Walsby AE (1997) Numerical integration of phytoplankton photosynthesis through time and depth in a water column. New Phytol 136:189-209

Wangersky PJ (1978) Lotka-Volterra population models. Annu Rev Ecol Syst 9:189-218

Wangersky PJ, Cunningham WJ (1957) Time lag in population models. Cold Spring Harbor Symp Quant Biol 22: 329-338

Wasmund N (1994) Phytoplankton periodicity in a eutrophic coastal water of the Baltic Sea. Int Rev Gesamten Hydrobiol 79:259-285

Wasmund N, Heerkloß R (1993) Seasonal and long-term succession of phytoplankton in shallow coastal water of the southern Baltic Sea. Stud Mater Oceanol 64:203-213

Wiedner C, Nixdorf B (1998) Success of chrysophytes, cryptophytes and dinoflagellates over blue-greens (cyanobacteria) during an extreme winter (1995/96) in eutrophic shallow lakes. Hydrobiologia 370:229-235

Zhen J, Ma Z (2002) Periodic solutions for delay differential equations model of plankton allelopathy. Comput Math Appl 44:491-500 
Appendix 1. Stability analysis for mixotrophic model

Consider model $(1,2)$ with constant parameter values. The system typically has non-trivial null-clines (curves upon which either $\mathrm{d} C / \mathrm{d} t=0$ or $\mathrm{d} A / \mathrm{d} t=0$ ) as shown in Fig. 2; a diagonal $A$ null-cline with a slope of -1 is given by:

$$
C=\left(1-\frac{\mu_{\mathrm{A}}}{r_{\mathrm{A}}}\right) K-A
$$

which intersects the $A$-axis at a positive value less than the carrying capacity $K$, and a parallel $C$ null-cline is given by:

$$
A=\left[1-\frac{\mu_{\mathrm{C}}-\left(1-p_{(T, L)}\right) \gamma m B}{p_{(T, L)} r_{\mathrm{C}}}\right] K-C
$$

which lies either below (for $p_{(T, L)}>0.5$ ) or above (when $p_{(T, L)}<0.5$ ) the $A$ null-cline (as in Fig. 2), depending on $p_{(T, L)}$. The null-clines, therefore, do not intersect, i.e. there is no non-trivial equilibrium. The 3 trivial equilibrium points are labelled $(a, b, c)$ and are, in $(A, C)$ coordinates:

a $(0,0)$

$b$ $\left(\left(1-\frac{\mu_{\mathrm{A}}}{r_{\mathrm{A}}}\right) K, 0\right)$

C

$$
\left(0,\left[1-\frac{\mu_{\mathrm{C}}-\left(1-p_{(T, L)}\right) \gamma m B}{p_{(T, L)} r_{\mathrm{C}}}\right] K\right)
$$

Consistent with standard Lotka-Volterra competition theory (e.g. Kot 2001), (0,0) is never stable, and exactly one of the other equilibria is the model's unique attractor (the remaining equilibrium is a saddle).

In the pathological case where:

$$
p_{(T, L)}=\frac{r_{\mathrm{A}}\left(\gamma m B-\mu_{\mathrm{C}}\right)}{\gamma m B r_{\mathrm{A}}-\mu_{\mathrm{A}} r_{\mathrm{C}}}
$$

both null-clines are identical and an ecologically unrealistic form of coexistence is possible. In short, it can be concluded that mixotrophy alone is insufficient to explain coexistence, let alone to capture any realistic population dynamics.
Appendix 2. Stability analysis for mixotrophic-allelopathic model

In contrast to the previous modifications (Expts $2 \& 3$ ), the model $(3,4)$ is not a trivial modification to the bifurcational structure of $(1,2)$. Typically its non-trivial null-clines (curves upon which either $\mathrm{d} C / \mathrm{d} t=0$ or $\mathrm{d} A / \mathrm{d} t=0$ ) are as shown in Fig. 3 ; a $C$ null-cline is given by:

$$
C=\frac{K}{r_{\mathrm{C}}}\left\{r_{\mathrm{C}}-\left[\frac{K}{(K-A)} \frac{\left(\mu_{\mathrm{C}}-\gamma m B\right)}{p_{(T, L)}}+\gamma m B\right]-A\right\}
$$

and a diagonal $A$ null-cline, identical to that in the nonallelopathic model, intersects the $A$-axis at a positive value less than the carrying capacity $K$. These null-clines intersect once, i.e. there is a unique non-trivial equilibrium $\left(A^{*}, C^{*}\right)$. The equilibrium point is:

$$
\begin{array}{ll}
\text { and } & A^{*}=K\left[1-\frac{\left(\mu_{\mathrm{C}}-\gamma m B\right) r_{\mathrm{A}}}{p\left(r_{\mathrm{C}} \mu_{\mathrm{A}}-\gamma m B r_{\mathrm{A}}\right)}\right] \\
& C^{*}=K\left[\frac{\left(\mu_{\mathrm{C}}-\gamma m B\right) r_{\mathrm{A}}}{p\left(r_{\mathrm{C}} \mu_{\mathrm{A}}-\gamma m B r_{\mathrm{A}}\right)}-\frac{\mu_{\mathrm{A}}}{r_{\mathrm{A}}}\right]
\end{array}
$$

The 3 trivial equilibrium points are, in $A, C$ coordinates:

$b$

C

$$
\begin{gathered}
\left(\left(1-\frac{\mu_{\mathrm{A}}}{r_{\mathrm{A}}}\right) K, 0\right) \\
\left(0,\left\{1+\left[\frac{(1-p) \gamma m B-\mu_{\mathrm{C}}}{p r_{\mathrm{C}}}\right]\right\} K\right)
\end{gathered}
$$

In the parameter regime specified in Table 1, linear stability analysis shows that equilibria $b$ and $c$ are never stable and that equilibrium $d$ is stable if and only if both $\left(r_{\mathrm{C}} \mu_{\mathrm{A}}-\mathrm{r}_{\mathrm{A}} \gamma m B\right) p>\mathrm{r}_{\mathrm{A}}\left(\mu_{\mathrm{C}}-\gamma m B\right)$ and $p r_{\mathrm{C}}+(1-p) \gamma m B-$ $\mu_{\mathrm{C}}>0$. In the realistic parameter space of Table 1 it can be shown that there is a saddle-node bifurcation when:

$$
p=\frac{r_{\mathrm{A}}\left(\mu_{\mathrm{C}}-\gamma m B\right)}{\left(r_{\mathrm{C}} \mu_{\mathrm{A}}-r_{\mathrm{A}} \gamma m B\right)}
$$

the coexisting equilibrium a becomes a stable node and equilibrium $d$ becomes a saddle, as $p$ increases through this value. In other words, the point when $p$ increases through

$$
p=\frac{r_{\mathrm{A}}\left(\mu_{\mathrm{C}}-\gamma m B\right)}{\left(r_{\mathrm{C}} \mu_{\mathrm{A}}-r_{\mathrm{A}} \gamma m B\right)}
$$

represents the transition between the scenarios of Fig. 3B and A. Numerical simulations (Fig. 4) confirm these analytical results for the situation when $r_{\mathrm{A}}$ and $r_{\mathrm{C}}$ are allowed to vary according to light and temperature conditions, i.e. the curve in Fig. 4 is in agreement with the above bifurcation condition.

Submitted: November 29, 2005; Accepted: April 28, 2006

Proofs received from author(s): November 20, 2006
Editorial responsibility: Alain Vézina (Contributing Editor), Dartmouth, Nova Scotia, Canada 